\title{
Do pentaploid hybrids mediate gene flow between tetraploid Senecio disjunctus and hexaploid S. carniolicus s. str. (S. carniolicus aggregate, Asteraceae)?
}

\author{
Andrea Peskoller $^{1} \cdot$ Lisa Silbernagl $^{1} \cdot$ Karl Hülber $^{2} \mathbb{D} \cdot$ Michaela Sonnleitner $^{2,3}$ (D) $\cdot$ Peter Schönswetter $^{1}$ (I)
}

Received: 11 February 2021 / Accepted: 30 March 2021 / Published online: 13 April 2021

(C) The Author(s) 2021

\begin{abstract}
Polyploids with odd-ploidy levels may play an important evolutionary role as they enable backcrosses with their parental cytotypes. We chose the ploidy-variable Senecio carniolicus species group to address the overarching question if pentaploid individuals, which occur at high frequencies in immediate contact zones of parental tetraploids and hexaploids, mediate effective interploidy gene flow. We employed a set of approaches including relative genome size (RGS) determination and viability tests of pollen, RGS of the embryo, viability tests and germination experiments of seeds, and RGS and survival experiments of seedlings to tackle the following specific questions. Is pollen of pentaploid individuals viable suggesting regular meiosis in spite of the odd-ploidy level? Are the five sets of chromosomes split into 2.5 compliments, or rather into two and three compliments? Do crossings between pentaploid individuals produce viable seeds and seedlings, suggesting that pentaploids are an independent evolutionary unit? We found that pollen stainability is not strongly reduced in pentaploids and that the five chromosome complements are most often split into 2.5 complements. Seeds originating from homoploid crossings of pentaploids show a very low viability whereas backcrosses with tetraploids or hexaploids were more successful. No significant difference in seedling survival was observed among the different crossings but seedlings emerging from $5 x 5 x$ crosses were significantly smaller than both, seedlings from backcrosses and from homoploid parental crosses. Altogether, our results indicate that pentaploids may play an important evolutionary role as mediators of gene flow but that they rather do not form an independent evolutionary unit.
\end{abstract}

Keywords Controlled crosses · Cytotypes $\cdot$ Flow cytometry $\cdot$ Hybrid cytotypes $\cdot$ Pollen fertility $\cdot$ Polyploidy

\section{Introduction}

Polyploidy is one of the most important evolutionary pathways in flowering plants and has significantly contributed to their diversification and radiation (McGrath and Lynch 2012; Husband et al. 2013; Madlung 2013; Weiss-Schneeweiss et al. 2013), for instance as most frequent mode of sympatric speciation (Otto and Whitton 2000). Many species—or

Peter Schönswetter

peter.schoenswetter@uibk.ac.at

1 Department of Botany, University of Innsbruck, Sternwartestraße 15, 6020 Innsbruck, Austria

2 Department of Botany and Biodiversity Research, University of Vienna, Rennweg 14, 1030 Vienna, Austria

3 Department of Botany, Natural History Museum Vienna, Burgring 7, 1010 Vienna, Austria groups of closely related species-comprise different ploidy cytotypes (for simplicity termed "cytotypes" from here on). Members of such polyploid complexes may form contact zones of two or even more cytotypes. Such areas of close spatial proximity of individuals of different ploidy-where cytotype diversity may have originated locally (i.e., primary contact zone) or via migration after allopatric divergence (secondary contact zone) - provide a unique opportunity to assess isolation mechanisms governing the coexistence of cytotypes (Petit et al. 1999; Kolár et al. 2017).

Usually polyploidization events induce instantaneous reproductive barriers between the neopolyploid and the ancestor due to a genomic dosage imbalance; however, the barrier is not necessarily complete (Coyne and Orr 2004; Mallet 2007). The degree of reproductive isolation of cytotypes, i.e., the frequency of heteroploid crosses and the subsequent formation of eventually viable and at least partially fertile hybrids, plays a crucial role for the long-term 
integrity of lineages in general (Barton and Hewitt 1985), and for the local maintenance of ploidy variation in contact zones in particular (Husband et al. 2013; Madlung 2013). For instance, gene flow via individuals of intermediate ploidy may lead to introgression and thus an increase of genetic diversity, transfer of adaptations, or the emergence of new adaptations in the receiving lineage (Soltis and Rieseberg 1986; Rieseberg et al. 1996; Petit et al. 1999). Among others, establishment, persistence and genetic integrity of hybrid cytotypes will be affected by the magnitude of niche divergence from parental cytotypes, thereby reducing competitive interactions and the incidence of heteroploid crosses. Niche differentiation among cytotypes was documented even in narrow contact zones (Mráz et al. 2012) and odd-ploid cytotypes were found in many model systems (e.g., Sabara et al. 2013). Their hybrid origin was confirmed in many cases, whereas little is known about their role in enabling gene flow between and introgression into their parental cytotypes (Kolár et al. 2017). This is especially true for ploidies higher than tetraploid as studied here; previous studies have mostly focussed on triploids originating in diploid-tetraploid contact zones (Ramsey and Schemske 1998; but see Kolár et al. 2009; Greiner and Oberprieler 2012; Sutherland and Galloway 2017; Sutherland et al. 2020).

Polyploids with odd-ploidy levels face difficulties in production of functional gametes owing to their genomic imbalance and are, therefore, expected to be highly sterile (Ramsey and Schemske 1998). Gametes of odd-ploids often show various ploidies (e.g. $x, 2 x, 3 x$ pollen in triploid Hieracium subgen. Pilosella and H. echioides; Krahulcová and Krahulec 2000; Peckert and Chrtek 2006) or aneuploidy (Henry et al. 2009). Detailed studies of meiosis exist for triploids (e.g. Tel-Zur et al. 2004; Henry et al. 2009; Wang et al. 2017), less is known from pentaploids (e.g. genus Rosa, which has a unique asymmetric meiotic system; e.g. Kovarik et al. 2008); however, irregularities in meiosis can be assumed to be similar to triploids. Some odd-ploid cytotypes produce functional gametes, resulting in viable (aneuploid) progeny (found in triploid crop species such as melon, banana, apple, poplar; Ezura et al. 1994; Osuji et al. 1997; Zhang and Park 2009; Wang et al. 2017), fewer examples are known from sexually reproducing wild species such as Tripleurospermum inodorum (Čertner et al. 2017). Even if functional gametes are usually produced at low frequency, they enable backcrossing with either parent in mixed ploidy contact zones (Kolář et al. 2017).

A well-suited system to study mechanisms of acrossploidy gene flow is provided by the Senecio carniolicus Willd. (syn. Jacobaea carniolica (Willd.) Schrank) species group comprising herbaceous perennials common on acidic bedrock in the alpine to subnival belt of the Eastern Alps and the Carpathians. In the Eastern Alps, this group constitutes an autopolyploid complex comprising the west-east vicariant diploids $S$. insubricus (Chenevard) R. Flatscher, Schneew. and Schönsw., and S. noricus R. Flatscher, Schneew. and Schönsw. (both $2 n=2 x=40$ ), as well as tetraploid $S$. disjunctus $\mathrm{R}$. Flatscher, Schneew. and Schönsw. $(2 n=4 x=80)$ and hexaploid $S$. carniolicus s. str. $(2 n=6 x=120$; Suda et al. 2007; Sonnleitner et al. 2010). To enhance readability, in the following, we refer to the latter two species by their cytotype. In contrast to the majority of heteroploid taxa, the $S$. carniolicus species group does not form a single or a few contact zones containing otherwise geographically well-separated cytotypes (Husband and Schemske 1998; Hardy et al. 2000; Mandáková and Münzbergová 2006; Španiel et al. 2008); instead, various combinations of species of different ploidy occur throughout major parts of the Eastern Alps (Suda et al. 2007; Sonnleitner et al. 2010).

Strong genetic divergence between the ancestral eastern diploid lineage (i.e., S. noricus) and its autopolyploid derivatives (Winkler et al. 2017) as well as consistent differentiation between tetraploids and hexaploids render ongoing polytopic origin of the polyploids unlikely (Winkler et al. 2017), which is in line with consistent morphological differentiation (Flatscher et al. 2015). The species are ecologically differentiated on a large scale (Sonnleitner et al. 2010) as well as within narrow contact zones (Schönswetter et al. 2007; Hülber et al. 2009, 2015). Crossability depends on the ploidy level. Whereas strong crossing barriers prevent or strongly reduce gene flow between diploids and polyploids, tetra- and hexaploids are highly interfertile (Sonnleitner et al. 2013). This is in line with the hypothesis that genome dosage effects, i.e. the deviation from a 2:1 ratio of maternal and paternal genomes in the endosperm, govern the level of interfertility between cytotypes (Johnston et al. 1980; Scott et al. 1998; Kinoshita 2007). Overall, a range-wide survey of natural populations revealed only low frequencies $(<1 \%)$ of hybrid cytotypes (Sonnleitner et al. 2010). In any event, individuals of different cytotypes commonly occur in close spatial proximity (sometimes $<1 \mathrm{~m}$; Hülber et al. 2009) and strongly overlap in flowering time (Winkler et al. 2017). This, alongside the generalistic behaviour of alpine pollinators (Olesen and Jordano 2002), precludes a strong pre-pollination isolation, rendering heteroploid pollination likely.

In the $S$. carniolicus species group, pentaploid $(2 n=5 x=100)$ individuals - in spite of their scarcity at the range-wide scale-occur in high frequencies in strictly localized immediate contact zones of both parental cytotypes, i.e. tetraploids and hexaploids (Hülber et al. 2015), and genetic data suggested massive local introgression of pentaploids into hexaploids (Winkler et al. 2017). Triggered by these observations, we employed a set of complementary experimental approaches targeting different crucial stages in the life cycle, i.e. pollen (relative genome size [RGS] determination via flow cytometry $[\mathrm{FCM}]$ and viability 
tests), "seeds" (RGS of the embryo, viability tests and germination experiment; we use the term "seed" instead of the correct "cypsela" to aid legibility) and seedlings (RGS and survival experiments) to tackle the following questions. (1) Is pollen of pentaploid individuals viable suggesting regular meiosis in spite of the odd-ploidy level, or is meiosis disturbed resulting in low fertility? (2) If the pollen fertility is high, are the five sets of chromosomes split in half into 2.5 compliments reflecting the situation in triploids, where 1.5-ploid pollen appears to prevail (Ramsey and Schemske 1998), or rather into two and three complete compliments? (3) Do crossings between pentaploid individuals produce viable seeds and seedlings, suggesting that pentaploids are an independent evolutionary unit? Alternatively, are rather backcrosses with the parental tetraploids and/or hexaploids successful? We emphasise that our study has two potential drawbacks. First, for methodological reasons, we only consider pollen and neglect egg cell ploidy. Second, due to the high chromosome numbers and the difficulty of obtaining high-quality chromosome spreads even from root tips of pentaploids, we refrained from performing chromosome counts, which would allow for a more direct evaluation of microsporocyte meiosis.

\section{Materials and methods}

\section{Plant material and artificial crosses}

We used plants of tetraploids, hexaploids and their pentaploid hybrids grown from seeds originating from controlled cross-pollinations conducted in 2009 east of Turracher Höhe (Gurktaler Alpen, Austria, N 46.91 E 13.92 at ca. 2250 m a.s.l.) and presented in Sonnleitner et al. (2013). Plants were cultivated in the alpine garden of the Botanical Garden of the University of Innsbruck situated at timberline on Mt. Patscherkofel (N 47.21 E 11.45) at ca. $2000 \mathrm{~m}$ a.s.l. Using individuals from a single location avoids the effects of ploidy, the focus of this study, to be confounded with those of geographic differentiation, due to, for instance, adaptation to different ecoclimatic conditions. Each of the two species and their pentaploid hybrid was crossed with a plant of the same ploidy (termed homoploid crosses in the following); additionally, each of the two species was crossed with their pentaploid hybrid (i.e., heteroploid backcrosses). The ploidy of all crossing partners was determined via flow cytometry (FCM) of silica-dried leaf material (see below). Each inflorescence serving either as pollen receptor or as pollen donor was bagged before anthesis using a small-meshed tissue to prevent uncontrolled pollen transfer. Hand pollinations were done by rubbing anthetic flower heads of mother plants and pollen donor plants. The three cytotypes flowered synchronously; hand pollination was done within ca. 2 weeks of uniformly cool and cloudy weather conditions. We observed no extreme temperatures, which could have enhanced the frequency of unreduced pollen (Ramsey and Schemske 1998). Inflorescences were kept in bags for 7-8 weeks, when seeds were mature and harvested. Seeds were stored at $4{ }^{\circ} \mathrm{C}$. Seeds were visually classified as potentially viable (firm and plump pericarp) and non-viable (empty pericarp; Sonnleitner et al. 2013). Viable seeds of each mother plant were split into two groups of equal size designated for germination and for cytotype determination via FCM (see below), which cannot be done in a non-destructive way for small seeds.

\section{Staining of pollen grains}

One disc floret each of 6,17 and 43 individuals of tetraploids, hexaploids and pentaploid hybrids, respectively, was fixed in Carnoy's fixative (96\% ethanol: glacial acetic acid $=3: 1$ ) and pollen was stained with aceto-carmine for $15 \mathrm{~min}$. For each individual, stainability of nuclei of 200 pollen grains was visually checked in a thoma chamber with an Olympus BH-2 microscope and $20 \times$ amplification.

\section{Germination experiment}

If available, 10 viable seeds per mother plant, resulting in a total of 1256 seeds, were germinated on moist filter paper in petri dishes exposed in a climate chamber (CLF Plant Climatics, PGC-6L) using settings closely resembling in situ conditions: day/night $14 / 10 \mathrm{~h}$, temperature $15 / 5^{\circ} \mathrm{C}$; temperature adaptation within $1 \mathrm{~h}, 90 \%$ constant relative humidity (rH), approximately $370 \mathrm{mmol}$ photons $\mathrm{m}^{-2} \mathrm{~s}^{-1}$ light (Powerstar, Osram neon lights) during day time. Petri dishes were watered and repositioned to avoid edge effects at daily intervals. Seedlings with fully expanded cotyledons were transplanted into multi-pot plates, each pot containing ca. $150 \mathrm{ml}$ of substrate (i.e., a mixture resembling natural soils, composed of composted leaves, ground earth, lava, turf, quartz sand, rock flour and pumice gravel) and further cultivated in a greenhouse at ca. $22{ }^{\circ} \mathrm{C}$ temperature and a day length of $14 \mathrm{~h}$. Every fourth day, the vitality of seedlings was assessed as alive or dead. After 70 days, one of the cotyledons was sampled for ploidy determination via FCM (initial analyses found no incidence of endopolyploidy in cotyledons: data not shown) and the dry weight of the remaining above-ground parts of the plant was determined.

\section{Flow cytometry}

As the floret morphology precluded emasculation, self-pollination could not be avoided, but was previously found to be low and similar among cytotypes (Sonnleitner et al. 2013). Thus, the quantitative effects of selfing on the measured fitness components (via, for instance, pollen competition 
or interference) are expected to be similar for all cytotypes. Given the observed prevalence of 2.5-ploid pollen (Fig. 1b), the origin of individuals emerging from heteroploid crosses can be identified as selfed or hybridogenic by showing the maternal ploidy or a ploidy intermediate between both parental cytotypes, respectively. Furthermore, because of the intractability of egg cell ploidy with the chosen approach, we only conducted crosses using pentaploids as pollen donors. We used FCM to discriminate the origin of viable seeds obtained from the crossings and of the seedlings surviving until the end of the germination experiment. We detected no seeds or seedlings with increased ploidy due to the involvement of unreduced gametes (defined as showing $>1.5 \times$ mean RGS of the combination of parental cytotypes termed "treatment" in the following).

Flow cytometry (FCM) of 4',6-diamidino-2-phenylindole (DAPI; final concentration $0.036 \mathrm{M}$ ) stained nuclei was used to estimate RGS of silica gel-dried samples (Suda and Trávníček 2006). The primary internal standard used to determine DNA amounts was Vicia faba cv. Inovec $(2 \mathrm{C}=26.90 \mathrm{pg})$. For seedlings, desiccated green leaf tissue of one cotyledon was chopped together with an appropriate amount of fresh reference standard and processed as described in Suda et al. (2007). The relative fluorescence intensity of 3000 particles was recorded using a Partec CyFlow Space flow cytometer (Partec, Münster, Germany). Partec FloMax software was used to evaluate the histograms. The RGS was calculated as ratio between the relative fluorescence of sample and standard. The reliability of the measurements was assessed by calculating coefficients of variation (CV) for the G1 peaks of both the analysed sample and
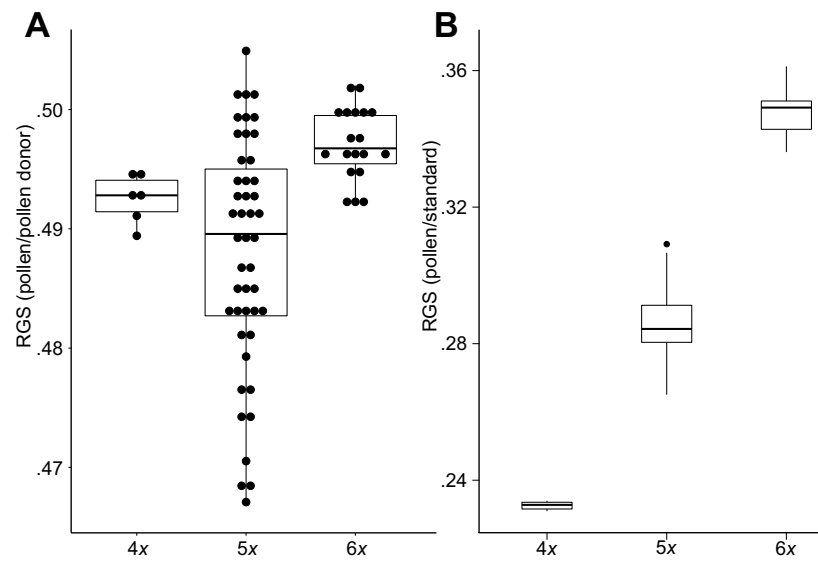

Fig. 1 Relative genome size (RGS) of pollen of members of the heteroploid Senecio carniolicus species group, i.e. tetraploid S. disjunctus, hexaploid S. carniolicus and their pentaploid hybrids, shown as a ratio of pollen and leaf samples of pollen donor plant (a) and ratio of pollen and leaf samples of Vicia faba used as standard (b). The dots in a represent individual pollen donor plants. Means are shown as horizontal lines; boxes indicate the inner $50 \%$ quantiles and whiskers span $1.5 \times$ of the interquartile range the reference standard. Analyses yielding a CV threshold of $>5 \%$ were manually gated as due to the small amount of leaf material a repetition was unfeasible.

The RGS of dry seeds was estimated adopting the methodology described above with the following modifications: (i) the samples were run on a flow cytometer ca. $30 \mathrm{~s}$ after the addition of the staining solution (longer incubation period resulted in a lower histogram quality), (ii) manual gating of the embryo peaks was applied in all cases, due to low peak quality. The flow histograms mostly consisted of two peaks, representing the internal reference standard and the embryo nuclei. Endosperm peaks were usually not visible.

The FCM of pollen grains followed the protocol from Kron and Husband (2012) with the following modifications: pollen was suspended in ice-cold Otto I buffer $(0.1 \mathrm{M}$ citric acid, $0.5 \%$ Tween 20 ) and stained with adding two rounds of $0.5 \mathrm{ml}$ Otto II buffer $\left(0.4 \mathrm{M} \mathrm{Na}_{2} \mathrm{HPO}_{4} \cdot 12 \mathrm{H}_{2} \mathrm{O}\right)$ supplemented with DAPI (Sigma, St. Louis, Missouri, USA) at a final concentration of $4 \mu \mathrm{g} / \mathrm{ml}$ and 2-mercaptoethanol $(2 \mu \mathrm{l} /$ $\mathrm{ml})$. Bursting filters with 20 and $30 \mu \mathrm{m}$ filter size were used for tetraploids and hexaploids, respectively, as hexaploid nuclei did not pass the smaller filter size. For pentaploids, both filter sizes yielded comparable results and $30 \mu \mathrm{m}$ filter size was finally used. To resolve the pollen from the bursting filter we again used Otto I, already containing nuclei of primary and secondary internal standard, prepared as described above. Vicia faba cv. Inovec served as primary internal standard and leaf material from the same plant as secondary internal standard, resulting in three peaks. We are aware that the peak derived from leaf material hides eventually present unreduced gametes, which were not the focus of our study. Further steps were as described above. RGS was calculated (1) as a ratio of pollen and secondary standard (pollen/pollen donor) and (2) as a ratio of pollen and primary standard (pollen/standard).

\section{Statistical analyses}

The effects of crossing partner ploidy on reproductive success were analysed by means of three fitness components of $F_{1}$ individuals. (1) Seed viability represents the state of seeds obtained from the artificial crossings classified as viable or non-viable; (2) survival of hybrid seedlings reflects the vitality of hybrid individuals at the end of the germination experiment coded as alive or dead; and (3) the size of hybrid seedlings is the above-ground dry weight of hybrid individuals measured at the end of the experiment. Whereas seed viability comprised the overall seed yield, only individuals with intermediate ploidy (referred to as hybrid seedlings in the following) were used to estimate survival and size of seedlings. The RGS ranges for classifying seeds/seedlings as selfed individuals were determined based on a visual 
inspection of the distribution of genome sizes (Supplementary Fig. 1). For the heteroploid crosses individuals outside the ranges defined in the "Results" section were considered to be hybrids.

We analysed the effects of parental ploidy on fitness components by means of linear mixed-effects models (LMM, in case of size of hybrid seedlings) or binomial generalised linear mixed-effects models (GLMM, in case of seed viability and survival of hybrid seedlings) as implemented in the functions "Imer" and "glmer" of the R package "Ime4" (Bates et al. 2015). Models relate one fitness component as response to the treatment as fixed-effect predictor. We compared homoploid pentaploid crosses $(5 x 5 x)$ to pooled parental homoploid crosses ( $4 x 4 x$ and $6 x 6 x)$ as well as to the heteroploid crosses. Since for these analyses, data of more than one seed or seedling from each pollinated individual were used, we accounted for the potential effects of this dependence by using mother plant as a grouping variable and allowing for a random intercept for each group. For the binomially distributed data of seed viability and survival of hybrid seedlings, we used the canonical logit link-function. To model the size of hybrid seedlings, Gaussian distributions of errors were assumed and the identity link was used accordingly. Parameters were estimated by restricted maximum likelihood in case of the LMM and based on the Laplacian approximation in case of the binomial GLMM. For the Gaussian models, the degrees of freedom were calculated using the Kenward-Roger approximation as implemented in the function "get_ddf_Lb" of the R package "pbkrtest" (Halekoh and Højsgaard 2014).

The ploidy of seedlings is only known when they survived until the end of the experiment. Thus, it is unknown whether a seed that failed to germinate or a seedling that died during the experiment originated from selfing or hybridisation, which makes a straightforward estimation of the survival of hybrid seedlings impossible. Therefore, we assumed an equal percentage of hybrid seeds exposed in the germination experiment and among the seeds analysed with FCM. A subset of the size $n \mathrm{Hyb}_{\text {dead }}$ was randomly selected among dead individuals and defined as hybrids in the survival models following the formula

$n \mathrm{Hyb}_{\text {dead }}=(n$ Total $* p)-n \mathrm{Hyb}_{\text {surv }}$,

where $n$ Total represents the number of seeds exposed in the germination experiment, $p$ is the proportion (ranging from 0 to 1 ) of hybrid seeds in the FCM analysis, and $n \mathrm{Hyb}_{\text {surv }}$ and $n \mathrm{Hyb}_{\text {dead }}$ are the numbers of surviving and dead hybrid seeds in the germination experiment, respectively. Coefficients and $z$ values given for models of seedling survival represent means of 100 repetitions of this random association of dead progeny to mother plants and subsequent model fitting. $P$ values of models of seedling survival were calculated using the mean of $z$-values.

All statistical analyses were computed in R 2.13.0.

\section{Results}

Staining of pollen of pentaploids showed no reduced stainability in comparison to tetraploid pollen and a somewhat reduced stainability in comparison to hexaploid pollen ( $4 x$ : $73.0 \pm 27.4 \% ; 5 x: 72.5 \pm 20.8 \% ; 6 x: 89.8 \pm 6.5 \%)$. Flow cytometry of pollen from 46 pentaploid plants supplemented by 6 tetraploid and 19 hexaploid plants revealed a highly similar RGS when expressed as ratio pollen: leaves of the pollen donor in all three cases $(4 x: 0.49 \pm 0.002$; $5 x$ : $0.49 \pm 0.010 ; 6 x: 0.49 \pm 0.003$; Fig. 1a) and no overlap of RGS when expressed as pollen: standard ratio $(4 x$ : $0.23 \pm 0.001 ; 5 x: 0.29 \pm 0.014 ; 6 x$ : 0.35 \pm 0.007 ; Fig. $1 b$ ).

A general description of the crossing and germination experiments is given in Table 1. Overall, seed viability is lower than in our previous study (Sonnleitner et al. 2013) most probably because of bad weather conditions during the

Table 1 General description of the experimental cross-pollinations among members of the heteroploid Senecio carniolicus species group, i.e. tetraploid $S$. disjunctus, hexaploid S. carniolicus and their

pentaploid hybrids, and a consecutive germination experiment using a subset of the emerging seeds in the climate chamber

\begin{tabular}{llllllllll}
\hline Treatment & $\begin{array}{l}\text { Indi- } \\
\text { viduals } \\
(\text { no. })\end{array}$ & $\begin{array}{l}\text { Florets } \\
\text { pollinated } \\
(\text { no. })\end{array}$ & $\begin{array}{l}\text { Seed } \\
\text { viability } \\
(\%)\end{array}$ & $\begin{array}{l}\text { Seeds cytotyped } \\
\text { (no.)/detected } \\
\text { hybrids }(\%)\end{array}$ & $\begin{array}{l}\text { RGS of seeds } \\
(\text { mean } \pm \text { SD) }\end{array}$ & $\begin{array}{l}\text { Exposed } \\
\text { seeds } \\
(\text { no. })\end{array}$ & $\begin{array}{l}\text { Surviving } \\
\text { seedlings } \\
(\text { no./\%) }\end{array}$ & $\begin{array}{l}\text { Seedlings } \\
\text { cytotyped (no.)/ } \\
\text { detected hybrids } \\
(\%)\end{array}$ & $\begin{array}{l}\text { RGS of } \\
\text { seedlings } \\
(\text { mean } \pm S D)\end{array}$ \\
\hline $4 x 4 x$ & 45 & 13,535 & 17.1 & 160 & $0.48 \pm 0.01$ & 358 & $212 / 59.2$ & 197 & $0.46 \pm 0.01$ \\
$4 x 5 x$ & 46 & 12,195 & 7.4 & $100 / 61$ & $0.54 \pm 0.02$ & 224 & $112 / 50$ & $102 / 50$ & $0.51 \pm 0.02$ \\
$5 x 5 x$ & 43 & 7807 & 0.5 & 16 & $0.62 \pm 0.04$ & 21 & $12 / 57.1$ & 9 & $0.59 \pm 0.04$ \\
$6 x 5 x$ & 43 & 6786 & 3.0 & $62 / 25.8$ & $0.64 \pm 0.02$ & 118 & $80 / 67.8$ & $73 / 12.3$ & $0.62 \pm 0.01$ \\
$6 x 6 x$ & 50 & 10,283 & 21.0 & 162 & $0.70 \pm 0.01$ & 327 & $214 / 65.4$ & 195 & $0.68 \pm 0.02$ \\
\hline
\end{tabular}

Treatment refers to the parental cytotype combinations applied in the experiment; the maternal parent is given first. For heteroploid crosses (i.e., $4 x 5 x$ and $6 x 5 x$ ), the mean RGS is calculated only from hybrid individuals 
pollinations. Seed viability (Fig. 2) was lowest in homoploid crosses of pentaploids ( $5 x 5 x$ ). Crosses with the parental cytotypes $(4 x 5 x, 6 x 5 x)$, and especially homoploid crosses of pooled parental cytotypes $(4 x 4 x, 6 x 6 x)$ revealed significantly higher seed viability (Table 2 ).

Based on the distribution of RGS values, seeds with RGS ranging from 0.46 to $0.49(4 x 4 x)$ and 0.68 to 0.72 $(6 x 6 x)$, and seedlings with $0.44-0.48(4 x 4 x)$ and $0.65-0.71$ $(6 x 6 x)$ were considered to be of the same ploidy as their parents (Supplementary Fig. 1). For the heteroploid crosses, individuals outside these ranges were classified as hybrids. Based on this categorisation, we detected $61.0 \%$ hybrid seeds and $50.0 \%$ hybrid seedlings in the
$4 x 5 x$ crosses, and $25.8 \%$ hybrid seeds and $12.3 \%$ hybrid seedlings in the $6 x 5 x$ crosses.

The survival of $5 x 5 x$ was neither significantly different from their pooled homoploid parental crosses nor from their backcrosses (Fig. 2, Table 2). In contrast, the size of $5 \times 5 x$ seedlings was significantly lower compared to both, pooled homoploid parental crosses and backcrosses $(4 x 5 x$, $6 x 5 x$; Fig. 2, Table 2). The two backcrossing treatments did neither differ in seed viability nor in the survival of hybrid seedlings, but $6 x 5 x$ seedlings were bigger than $4 x 5 x$ seedlings.
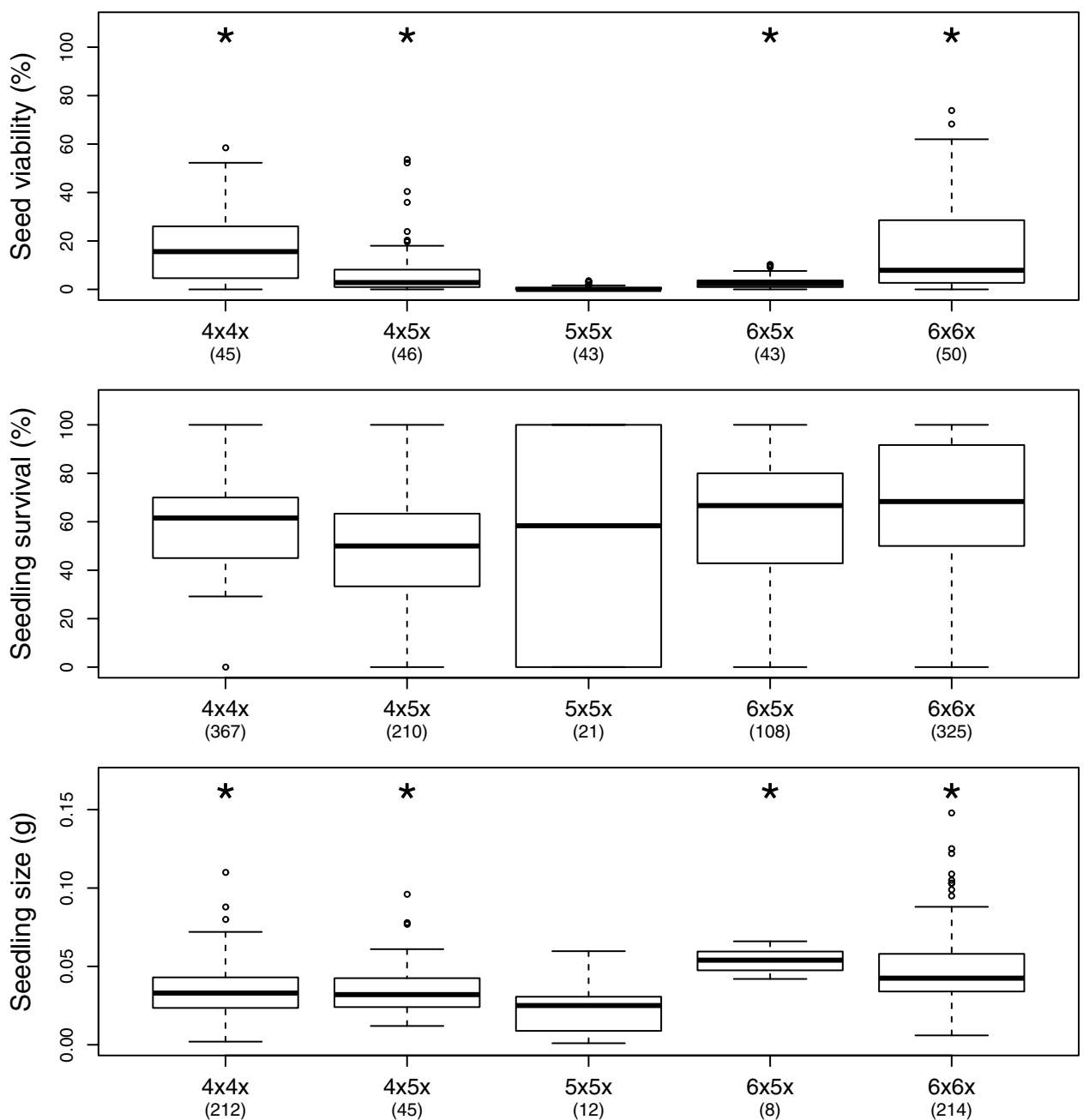

Fig. 2 Fitness components obtained from artificial crosses among members of the heteroploid Senecio carniolicus species group, i.e. tetraploid S. disjunctus, hexaploid S. carniolicus and their pentaploid hybrids, as well as backcrosses of the parental lineages as mother plant with the hybrid as pollen donor. Seedling survival represents the proportion of seeds of each mother plant still alive at the end of the germination experiment. Seedling size was measured as aboveground dry weight after 70-day exposure. The $x$-axis labels refer to the cytotypes of the parents with the maternal cytotype given first.
Asterisks indicate crosses significantly different from homoploid pentaploid crosses $(5 x 5 x)$; parental homoploid crosses $(4 x 4 x$ and $6 x 6 x)$ were pooled in this analysis (see Table 2 for details). Heteroploid crosses $(4 x 5 x, 6 x 5 x)$ differed significantly from each other only for seedling size. Values in brackets for seed viability, seedling survival and seedling size represent the number of mother plants used in the crosses, the number of seeds exposed in the germination experiment and the number of surviving seedlings, respectively 
Table 2 Comparisons of fitness components (seed viability, survival of seedlings, size of seedlings) of crosses among members of the heteroploid Senecio carniolicus species group, i.e. tetraploid S. disjunctus, hexaploid S. carniolicus and their pentaploid hybrids

\begin{tabular}{lccr}
\hline Comparison of treatment & Coefficient \pm SE & $z$-or $t$-value & $p$-value \\
\hline Seed viability & & & \\
$(4 x 4 x, 6 x 6 x) \leftrightarrow 5 x 5 x$ & $-1.36 \pm 0.13$ & -10.49 & $<0.001$ \\
$6 x 5 x \leftrightarrow 5 x 5 x$ & $-0.97 \pm 0.18$ & -5.39 & $<0.001$ \\
$4 x 5 x \leftrightarrow 5 x 5 x$ & $-1.45 \pm 0.25$ & -5.87 & $<0.001$ \\
$6 x 5 x \leftrightarrow 4 x 5 x$ & $0.32 \pm 0.21$ & 1.57 & 0.117 \\
Survival of hybrid seedlings & & \\
$(4 x 4 x, 6 x 6 x) \leftrightarrow 5 x 5 x$ & $0.09 \pm 0.19$ & 0.48 & 0.628 \\
$6 x 5 x \leftrightarrow 5 x 5 x$ & $-0.70 \pm 0.54$ & -1.31 & 0.190 \\
$4 x 5 x \leftrightarrow 5 x 5 x$ & $-0.49 \pm 0.32$ & -1.54 & 0.123 \\
$6 x 5 x \leftrightarrow 4 x 5 x$ & $-0.09 \pm 0.34$ & -0.28 & 0.781 \\
Size of hybrid seedlings & & & \\
$(4 x 4 x, 6 x 6 x) \leftrightarrow 5 x 5 x$ & $-0.01 \pm 0.002$ & -2.74 & 0.007 \\
$6 x 5 x \leftrightarrow 5 x 5 x$ & $-0.02 \pm 0.003$ & -5.54 & 0.002 \\
$4 x 5 x \leftrightarrow 5 x 5 x$ & $-0.01 \pm 0.003$ & -2.20 & 0.039 \\
$6 x 5 x \leftrightarrow 4 x 5 x$ & $-0.01 \pm 0.003$ & -3.17 & 0.004 \\
\hline
\end{tabular}

Positive coefficients indicate higher values of the right treatment

\section{Discussion}

Odd-ploidy cytotypes may play a crucial role in the evolution of polyploid complexes. Amongst other, they may increase genetic diversity and confer the transfer of existing or the emergence of newly evolved adaptations in the receiving ploidy level (Rieseberg et al. 1996). Here, we used a polyploid complex, the Senecio carniolicus species group, as a model system to shed light on the role of pentaploid hybrids, which occur at high frequencies in strictly localised zones of immediate contact between tetraploids and hexaploids (Winkler et al. 2017). We did this by applying a set of complementary experimental approaches to early stages in the life cycle, i.e. pollen, seeds and seedlings.

Pollen stainability, which we used as an approximation of pollen viability, is not strongly reduced in pentaploid individuals as compared to the parental tetraploids and hexaploids. Specifically, it is $15 \%$ lower than in hexaploids, but almost exactly as high as in tetraploids, thus exceeding $70 \%$. Such high stainability is unexpected as gametes of oddploidy individuals have been commonly considered to be strongly compromised by irregularities during meiosis due to the uneven number of chromosome sets ("triploid block"; Marks 1966; Felber 1991; Köhler et al. 2010). In line with recent evidence from Populus, we emphasise that the high stainability does likely overestimate the functionality of the pollen (Wang et al. 2017). However, the production of viable seeds under the involvement of pollen produced by pentaploid individuals of the $S$. carniolicus group clearly indicates that at least a limited number of pollen is viable (Table 1).
Our results thus reflect the situation in triploid Arabidopsis thaliana, where meiosis produced viable gametes (Henry et al. 2009).

During meiosis of microsporocytes, the five chromosome complements of pentaploids are most often split into 2.5 complements (Lepší et al. 2019), rather than into two and three complements. Such a division is supported by the lack of overlap in the RGS - calculated relative to the reference standard Vicia faba - among pollen produced by tetra-, penta- and hexaploids (Fig. 1b) and, based on chromosome counts, was previously found to be the prevalent meiotic pathway in triploids (Ramsey and Schemske 1998). Reports of 2.5-ploid gametes are scarce but their occurrence in pentaploid Dryopteris $\times$ critica (Ekrt and Koutecký 2016) may indicate that they are broadly distributed across vascular plants. Whereas 2.5 -ploid pollen clearly prevails, the pollen produced by pentaploids exhibits a higher variability in RGS-expressed as the ratio between pollen and somatic nuclei of the same individual-than seen in pollen of tetraploids and hexaploids (Fig. 1a). This is in line with the expectation that most gametes produced by odd-ploids will have unbalanced and variable chromosome numbers caused by a failure to separate odd-numbered chromosome sets during meiosis (Henry et al. 2009; Köhler et al. 2010; Wang et al. 2017; Lepší et al. 2019).

Seeds originating from homoploid crossings of pentaploids ( $5 x 5 x$ ) show a very low viability (Tables 1, 2, Fig. 2). Specifically, out of almost 8000 pollinated florets, only 42 seeds $(0.54 \%)$ emerged, which suggests that the high pollen stainability discussed above is no adequate proxy for its fertility (Wang et al. 2017). The low seed viability renders the hypothesis unlikely that pentaploids form an independent evolutionary unit and may eventually build up pure populations, thereby escaping minority cytotype exclusion (Levin 1975). In contrast, backcrosses of pentaploids with the parental tetraploids or hexaploids yielded a significantly higher seed viability, without differences between $6 x 5 x$ and $4 x 5 x$ crosses (Table 2). The data, thus, do not support the hypotheses that backcrosses with either parent will produce mainly nonviable progeny due to the triploid block, and that rare survivors with unbalanced chromosome numbers will be mostly sterile because of a failure to separate oddnumbered chromosome sets during meiosis (Comai 2005; Köhler et al. 2010). Instead, our results are both in line with evidence from $A$. thaliana showing that gametes and zygotes are viable in spite of aneuploidy (Henry et al. 2009), as well as with the situation in Knautia, where aneuploid offspring of pentaploids was frequently found in a hybrid zone of tetraploid $K$. arvensis and hexaploid $K$. dipsacifolia (Kolář et al. 2009).

Once the seeds had germinated, no significant difference in seedling survival until the end of the experiment was observed among the different crossings (Table 2) indicating 
that survival of odd-ploid or even aneuploid individuals was not compromised as compared to individuals with an even number of complete chromosome sets. However, this result may also be-at least partly-explained by the low sample size of $5 x 5 x$ individuals (Table 1, Fig. 2). We emphasise, however, that the artificial conditions in a climate chamber and a greenhouse cannot replicate all the selective forces of the harsh alpine environment. Furthermore, the temporal constraints of an experimental approach prevent evaluating the long-term survival as well as the degree of fertility.

Seedlings emerging from $5 x 5 x$ crosses were significantly smaller than both, seedlings from backcrosses and from homoploid parental crosses (Table 2). This result contrasts the lack of differences in seedling survival discussed above and may indicate that even if individuals emerging from $5 x 5 x$ crosses do not necessarily have a higher probability of dying, their growth is indeed compromised as compared to the other treatments, even if the backcrosses with the parents will certainly be aneuploid. The size of $6 x 5 x$ seedlings exceeded that of $4 x 5 x$ seedlings (Table 2), most probably because higher ploidy levels result in bigger cell sizes and thus in taller plants (Lumaret et al. 1987; Lindner and Garcia 1997). A positive association between plant size and ploidy level was also observed in the $S$. carniolicus species group (Flatscher et al. 2015).

Finally, we emphasise that the experimental data presented here do not support our previous, AFLP-based hypothesis that in natural contact zones of tetraploids and hexaploids, pentaploids show strong introgressive hybridization with hexaploids as opposed to strong barriers towards tetraploids (Winkler et al. 2017). We speculate that the direction of introgression inferred by the employed software NewHybrids, which is at least not explicitly recommended for analysis of heteroploid datasets (Anderson and Thompson 2002; Anderson 2008), may have been distorted by the presence of different ploidy levels, but simulation studies would be necessary to confirm this.

Altogether, our results indicate that it is unlikely that pentaploids form an independent evolutionary unit. However, as also shown by the frequent occurrence of introgressive hybridization involving pentaploids beyond the $F_{1}$ generation inferred from genetic data (Winkler et al. 2017; uncertainty concerning the direction of introgression is discussed in the previous paragraph), pentaploids may play a role as introgression vectors between tetraploids and hexaploids. Indeed, re-evaluation of the raw RGS data presented in our previous observational field study (Winkler et al. 2017) suggests that several individuals showed a RGS intermediate between tetraploids and pentaploids while intermediates between pentaploids and hexaploids were very rare. Such introgressive hybridisation across ploidy levels could lead, amongst others, to a broadening of the receiving cytotype's ecological niche (Arnold 2004; Choler et al. 2004).
Supplementary Information The online version contains supplementary material available at https://doi.org/10.1007/s00035-021-00254-x.

Acknowledgements We thank Daniel Schlorhaufer, Martina Imhiavan and the other gardeners of the Botanical Garden of the University of Innsbruck for taking excellent care of our Senecio plants. Philipp Gostner conducted the pollen staining in the frame of his bachelor thesis supervised by PS. Johanna Wagner provided valuable input on pollen fertility tests. Martin Čertner and Filip Kolář provided insightful feedback on previous versions of the manuscript.

Authors' contributions Conceptualization: AP, KH, PS; methodology: AP, KH, PS; formal analysis and investigation: AP, LS, KH; writingoriginal draft preparation: AP, LS, MS, PS; writing — review and editing: all authors; supervision: PS.

Funding Open access funding provided by University of Innsbruck and Medical University of Innsbruck. Lab costs and travel expenses were covered by the regular budget provided by the University of Innsbruck.

Availability of data and materials Yes, on request.

Code availability Not applicable.

\section{Declarations}

Conflict of interest None.

Open Access This article is licensed under a Creative Commons Attribution 4.0 International License, which permits use, sharing, adaptation, distribution and reproduction in any medium or format, as long as you give appropriate credit to the original author(s) and the source, provide a link to the Creative Commons licence, and indicate if changes were made. The images or other third party material in this article are included in the article's Creative Commons licence, unless indicated otherwise in a credit line to the material. If material is not included in the article's Creative Commons licence and your intended use is not permitted by statutory regulation or exceeds the permitted use, you will need to obtain permission directly from the copyright holder. To view a copy of this licence, visit http://creativecommons.org/licenses/by/4.0/.

\section{References}

Anderson EC (2008) Bayesian inference of species hybrids using multilocus dominant genetic markers. Philos Trans R Soc Lond Ser B Biol Sci 363:2841-2850. https://doi.org/10.1098/rstb.2008.0043

Anderson EC, Thompson EA (2002) A model-based method for identifying species hybrids using multilocus genetic data. Genetics 160:1217-1229. https://doi.org/10.1093/genetics/160.3.1217

Arnold ML (2004) Transfer and origin of adaptations through natural hybridization: were Anderson and Stebbins right? Plant Cell 16:562-570. https://doi.org/10.1105/tpc. 160370

Barton NH, Hewitt GM (1985) Analysis of hybrid zones. Annu Rev Ecol Syst 16:113-148. https://doi.org/10.1146/annurev.es.16. 110185.000553

Bates D, Maechler M, Bolker B, Walker S (2015) lme4: linear mixedeffects models using Eigen and S4. R package version 11-10

Čertner M, Fenclová E, Kúr P, Kolář F, Koutecký P, Krahulcová A, Suda J (2017) Evolutionary dynamics of mixed-ploidy populations in an annual herb: dispersal, local persistence and recurrent 
origins of polyploids. Ann Bot 120:303-315. https://doi.org/10. 1093/aob/mcx032

Choler P, Erschbamer B, Tribsch A, Gielly L, Taberlet P (2004) Genetic introgression as a potential to widen a species' niche: insights from alpine Carex curvula. Proc Natl Acad Sci USA 101:171-176. https://doi.org/10.1073/pnas.2237235100

Comai L (2005) The advantages and disadvantages of being polyploid. Nat Rev Genet 6:836-846. https://doi.org/10.1038/nrg1711

Coyne JA, Orr HA (2004) Speciation. Sinauer Associates, Sunderland, MA

Ekrt L, Koutecký P (2016) Between sexual and apomictic: unexpectedly variable sporogenesis and production of viable polyhaploids in the pentaploid fern of the Dryopteris affinis agg. (Dryopteridaceae). Ann Bot 117:97-106. https://doi.org/10.1093/aob/ mev152

Ezura H, Kikuta I, Oosawa K (1994) Production of aneuploid melon plants following in vitro culture of seeds from a triploid $\mathrm{x}$ diploid cross. Plant Cell Tiss Org Cult 38:61-63. https://doi.org/10.1007/ bf00034445

Felber F (1991) Establishment of a tetraploid cytotype in a diploid population: effect of relative fitness of the cytotypes. J Evol Biol 4:195-207. https://doi.org/10.1046/j.1420-9101.1991.4020195.x

Flatscher R, Escobar García P, Hülber K, Sonnleitner M, Winkler M, Saukel J, Schneeweiss GM, Schönswetter P (2015) Underestimated diversity in one of the world's best studied mountain ranges: the polyploid complex of Senecio carniolicus (Asteraceae) contains four species in the European Alps. Phytotaxa 213:1-21. https://doi.org/10.11646/phytotaxa.213.1.1

Greiner R, Oberprieler C (2012) The role of inter-ploidy block for reproductive isolation of the diploid Leucanthemum pluriflorum $\mathrm{Pau}$ (Compositae, Anthemideae) and its tetra- and hexaploid relatives. Flora 207:629-635. https://doi.org/10.1016/j.flora.2012.07. 001

Halekoh U, Højsgaard S (2014) A Kenward-Roger approximation and parametric bootstrap methods for tests in linear mixed modelsthe R package pbkrtest. J Stat Softw 59:1-32

Hardy OJ, Vanderhoeven S, De Loose M, Meerts P (2000) Ecological, morphological and allozymic differentiation between diploid and tetraploid knapweeds (Centaurea jacea) from a contact zone in the Belgian Ardennes. New Phytol 146:281-290. https://doi.org/ 10.1046/j.1469-8137.2000.00631.x

Henry IM, Dilkes BP, Tyagi AP, Lin HY, Comai L (2009) Dosage and parent-of-origin effects shaping aneuploid swarms in A. thaliana. Heredity 103:458-468. https://doi.org/10.1038/hdy.2009.81

Hülber K, Sonnleitner M, Flatscher R, Berger A, Dobrovsky R, Niessner S, Nigl T, Schneeweiss GM, Kubešová M, Rauchová J, Suda J, Schönswetter P (2009) Ecological segregation drives fine-scale cytotype distribution of Senecio carniolicus in the Eastern Alps. Preslia 81:309-319

Hülber K, Sonnleitner M, Suda J, Krejčíková J, Schönswetter P, Schneeweiss GM, Winkler M (2015) Ecological differentiation, lack of hybrids involving diploids, and asymmetric gene flow between polyploids in narrow contact zones of Senecio carniolicus (syn. Jacobaea carniolica, Asteraceae). Ecol Evol 5:1224-1234. https://doi.org/10.1002/ece3.1430

Husband BC, Schemske DW (1998) Cytotype distribution at a diploidtetraploid contact zone in Chamerion (Epilobium) angustifolium (Onagraceae). Am J Bot 85:1688-1694. https://doi.org/10.2307/ 2446502

Husband BC, Baldwin S, Suda J (2013) The incidence of polyploidy in natural plant populations: major patterns and evolutionary processes. In: Greilhuber J, Dolezel J, Wendel JF (eds) Plant genome diversity, vol 2. Springer, Vienna, pp 255-276.https://doi.org/10. 1007/978-3-7091-1160-4_16

Johnston SA, den Nijs TPM, Peloquin SJ, Hanneman RE Jr (1980) The significance of genic balance to endosperm development in interspecific crosses. Theor Appl Genet 57:5-9. https://doi.org/ 10.1007/BF00276002

Kinoshita T (2007) Reproductive barrier and genomic imprinting in the endosperm of flowering plants. Genes Genet Syst 82:177-186. https://doi.org/10.1266/ggs.82.177

Köhler C, Mittelsten Scheid O, Erilova A (2010) The impact of the triploid block on the origin and evolution of polyploid plants. Trends Genet 26:142-148. https://doi.org/10.1016/j.tig.2009.12.006

Kolář F, Stech M, Trávníček P, Rauchová J, Urfus T, Vít P, Kubešová M, Suda J (2009) Towards resolving the Knautia arvensis agg. (Dipsacaceae) puzzle: primary and secondary contact zones and ploidy segregation at landscape and microgeographic scales. Ann Bot 103:963-974. https://doi.org/10.1093/aob/mcp016

Koláŕ F, Čertner M, Suda J, Schönswetter P, Husband BC (2017) Mixed-ploidy species: progress and opportunities in polyploid research. Trends Plant Sci 22:1041-1055. https://doi.org/10. 1016/j.tplants.2017.09.011

Kovarik A, Werlemark G, Leitch AR, Souckova-Skalicka K, Lim YK, Khaitová L, Koukalova B, Nybom H (2008) The asymmetric meiosis in pentaploid dogroses (Rosa sect. Caninae) is associated with a skewed distribution of rRNA gene families in the gametes. Heredity 101:359-367. https://doi.org/10.1038/ hdy. 2008.63

Krahulcová A, Krahulec F (2000) Offspring diversity in Hieracium subgen. Pilosella (Asteraceae): new cytotypes from hybridization experiments and from open pollination. Fragm Florist Geob 45:239-255

Kron P, Husband BC (2012) Using flow cytometry to estimate pollen DNA content: improved methodology and applications. Ann Bot 110:1067-1078. https://doi.org/10.1093/aob/mcs167

Lepší M, Koutecký P, Nosková J, Lepší P, Urfus T, Rich TCG (2019) Versatility of reproductive modes and ploidy level interactions in Sorbus s.1. (Malinae, Rosaceae). Bot J Linn Soc 191:502522. https://doi.org/10.1093/botlinnean/boz054

Levin DA (1975) Minority cytotype exclusion in local plant populations. Taxon 24:35-43. https://doi.org/10.2307/1218997

Lindner R, Garcia A (1997) Genetic differences between natural populations of diploid and tetraploid Dactylis glomerata ssp. izcoi. Grass Forage Sci 52:291-297. https://doi.org/10.1111/j. 1365-2494.1997.tb02359.x

Lumaret R, Guillerm JL, Delay J, Ait Lhaj Loutfi A, Izco J, Jay M (1987) Polyploidy and habitat differentiation in Dactylis glomerata L. from Galicia (Spain). Oecologia 73:436-446. https:// doi.org/10.1007/BF00385262

Madlung A (2013) Polyploidy and its effect on evolutionary success: old questions revisited with new tools. Heredity 110:99-104. https://doi.org/10.1038/hdy.2012.79

Mallet J (2007) Hybrid speciation. Nature 446:279-283. https://doi. org/10.1038/nature05706

Mandáková T, Münzbergová Z (2006) Distribution and ecology of cytotypes of the Aster amellus aggregates in the Czech Republic. Ann Bot 98:845-856. https://doi.org/10.1093/aob/mcl165

Marks GE (1966) The origin and significance of intraspecific polyploidy: experimental evidence from Solanum chacoense. Evolution 20:552-557. https://doi.org/10.1111/j.1558-5646.1966. tb03385.x

McGrath CL, Lynch M (2012) Evolutionary significance of wholegenome duplication. In: Soltis PS, Soltis DE (eds) Polyploidy and genome evolution. Springer, Berlin, Heidelberg, pp 1-20. https://doi.org/10.1007/978-3-642-31442-1_1

Mráz P, Španiel S, Keller A, Bowmann G, Farkas A, Šingliarová B, Rohr RP, Broennimann O, Müller-Schärer H (2012) Anthropogenic disturbance as a driver of microspatial and microhabitat segregation of cytotypes of Centaurea stoebe and cytotype interactions in secondary contact zones. Ann Bot 110:615-627. https://doi.org/10.1093/aob/mcs120 
Olesen JM, Jordano P (2002) Geographic patterns in plant-pollinator mutualistic networks. Ecology 83:2416-2424. https://doi.org/ $10.2307 / 3071803$

Osuji J, Vuylsteke D, Ortiz R (1997) Ploidy variation in hybrids from interploid $3 x \times 2 x$ crosses in Musa. Tropicultura 15:37-39

Otto SP, Whitton J (2000) Polyploid incidence and evolution. Annu Rev Genet 34:401-437. https://doi.org/10.1146/annurev.genet. 34.1.401

Peckert T, Chrtek J (2006) Mating interactions between coexisting diploid, triploid and tetraploid cytotypes of Hieracium echioides (Asteraceae). Folia Geobot 41:323-334

Petit C, Bretagnolle F, Felber F (1999) Evolutionary consequences of diploid-polyploid hybrid zones in wild species. Trends Ecol Evol 14:306-311. https://doi.org/10.1016/S0169-5347(99) 01608-0

Ramsey J, Schemske DW (1998) Pathways, mechanisms, and rates of polyploid formation in flowering plants. Annu Rev Ecol Syst 29:467-501. https://doi.org/10.1146/annurev.ecolsys.29.1.467

Rieseberg LH, Sinervo B, Linder CR, Ungerer MC, Arias DM (1996) Role of gene interactions in hybrid speciation: evidence from ancient and experimental hybrids. Science 272:741-745. https:// doi.org/10.1126/science.272.5262.741

Sabara HA, Kron P, Husband BC (2013) Cytotype coexistence leads to triploid hybrid production in a diploid-tetraploid contact zone of Chamerion angustifolium (Onagraceae). Am J Bot 100:962-970. https://doi.org/10.3732/ajb.1200583

Schönswetter P, Lachmayer M, Lettner C, Prehsler D, Rechnitzer S, Reich DS, Sonnleitner M, Wagner I, Hülber K, Schneeweiss GM, Trávníček P, Suda J (2007) Sympatric diploid and hexaploid cytotypes of Senecio carniolicus (Asteraceae) in the Eastern Alps are separated along an altitudinal gradient. J Plant Res 120:721-725. https://doi.org/10.1007/s10265-007-0108-x

Scott RJ, Spielman M, Bailey J, Dickinson HG (1998) Parent-of-origin effects on seed development in Arabidopsis thaliana. Development 125:3329-3341

Soltis DE, Rieseberg LH (1986) Autopolyploidy in Tolmiea menziesii (Saxifragaceae): genetic insights from enzyme electrophoresis. Am J Bot 73:310-318. https://doi.org/10.1002/j.1537-2197.1986. tb08534.X

Sonnleitner M, Flatscher R, Escobar García P, Rauchová J, Suda J, Schneeweiss GM, Hülber K, Schönswetter P (2010) Distribution and habitat segregation on different spatial scales among diploid, tetraploid and hexaploid cytotypes of Senecio carniolicus (Asteraceae) in the Eastern Alps. Ann Bot 106:967-977. https://doi.org/ 10.1093/aob/mcq192

Sonnleitner M, Weis B, Flatscher R, Escobar García P, Suda J, Krejčíková J, Schneeweiss GM, Winkler M, Schönswetter P, Hülber K (2013) Parental ploidy strongly affects offspring fitness in heteroploid crosses among three cytotypes of autopolyploid
Jacobaea carniolica (Asteraceae). PLoS One 8:e78959. https:// doi.org/10.1371/journal.pone.0078959

Španiel S, Marhold K, Hodálová I, Lihová J (2008) Diploid and tetraploid cytotypes of Centaurea stoebe (Asteraceae) in Central Europe: morphological differentiation and cytotype distribution patterns. Folia Geobot 43:131-158

Suda J, Trávníček P (2006) Estimation of relative nuclear DNA content in dehydrated plant tissues by flow cytometry. Curr Protoc Cytom 38:7.30.31-37.30.14. https://doi.org/10.1002/0471142956.cy073 0 s 38

Suda J, Weiss-Schneeweiss H, Tribsch A, Schneeweiss GM, Trávníček P, Schönswetter P (2007) Complex distribution patterns of di-, tetra-, and hexaploid cytotypes in the European high mountain plant Senecio carniolicus (Asteraceae). Am J Bot 94:1391-1401. https://doi.org/10.3732/ajb.94.8.1391

Sutherland BL, Galloway LF (2017) Postzygotic isolation varies by ploidy level within a polyploid complex. New Phytol 213:404412. https://doi.org/10.1111/nph.14116

Sutherland BL, Miranda-Katz T, Galloway LF (2020) Strength in numbers? Cytotype frequency mediates effect of reproductive barriers in mixed-ploidy arrays. Evolution 74:2281-2292. https://doi.org/ 10.1111/evo.14077

Tel-Zur N, Abbo S, Mizrahi Y (2004) Cytogenetics of semi-fertile triploid and aneuploid intergeneric vine cacti hybrids. J Hered 96:124-131. https://doi.org/10.1093/jhered/esi012

Wang J, Huo B, Liu W, Li D, Liao L (2017) Abnormal meiosis in an intersectional allotriploid of Populus L. and segregation of ploidy levels in $2 x \times 3 x$ progeny. PLOS One 12:e181767. https://doi. org/10.1371/journal.pone.0181767

Weiss-Schneeweiss H, Emadzade K, Jang TS, Schneeweiss GM (2013) Evolutionary consequences, constraints and potential of polyploidy in plants. Cytogenet Genome Res 140:137-150. https:// doi.org/10.1159/000351727

Winkler M, Escobar García P, Gattringer A, Sonnleitner M, Hülber K, Schönswetter P, Schneeweiss GM (2017) A novel method to infer the origin of polyploids from amplified fragment length polymorphism data reveals that the alpine polyploid complex of Senecio carniolicus (Asteraceae) evolved mainly via autopolyploidy. Mol Ecol Resour 17:877-892. https://doi.org/10.1111/ 1755-0998.12641

Zhang C, Park S (2009) Aneuploid production from crosses with diploid and triploid in apple tree. Hortic Environ Biotechnol 50:203-207

Publisher's Note Springer Nature remains neutral with regard to jurisdictional claims in published maps and institutional affiliations. 